\title{
Pembuatan Media Pembelajaran Berbasis Socrative Untuk Meningkatkan Literasi Digital Guru di Kecamatan Pangkalan Kuras
}

\author{
Abdullah $^{1}$, Jimmi Copriady $^{2}$, Betty Holiwarni ${ }^{3}$, Herdini $^{4}$, Ardiansyah $^{5}$ \\ Pendidikan Kimia, FKIP, Universitas Riau \\ 1abdoe171@gmail.com \\ 2jimmiputra@yahoo.co.id \\ ${ }^{3}$ warniholy@gmail.com \\ herdinimunir@yahoo.co.id \\ 5 ardiansyah3344@gmail.com
}

\begin{abstract}
ABSTRAK
Kompetensi yang dibutuhkan di era Industri 4.0 salah satunya adalah literasi digital. Literasi digital adalah kemampuan menggunakan teknologi informasi dan komunikasi (TIK) untuk mendapatkan informasi dan memilahnya. Kemampuan TIK guru di Kecamatan Pangkalan Kuras Kabupaten Pelalawan sudah cukup baik. Indikasinya adalah sebagian besar guru telah bisa menggunakan media sosial yang diakses melalui smartphone dan netbook pribadi. Namun, kemampuan ini belum dimanfaatkan untuk menerapkan proses pembelajaran berbasis digital di kelas. Hal ini disebabkan guru masih memiliki keterbatasan menggunakan smartphone atau netbook sebagai media pembelajaran online. Program Studi Pendidikan Kimia Universitas Riau menawarkan pelatihan pembuatan media pembelajaran digital berbasis Socrative untuk guru di Kecamatan Pangkalan Kuras sebagai sebagai salah satu kegiatan pengabdian kepada masyarakat. Guru antusias dalam mengikuti pelatihan yang diadakan. Sebagian guru mampu menerapkan pembelajaran berbasis Socrative di kelas. Sedangkan sebagian lagi, tidak bisa menerapkan pembelajaran berbasis digital di kelas karena minimnya siswa yang mempunyai smartphone serta adanya peraturan sekolah yang tidak membolehkan siswa menggunakan smartphone di sekolah.
\end{abstract}

Kata kunci: Socrative, Literasi Digital, Pembelajaran Berbasis Socrative

\section{ABSTRACT}

One of the competencies needed in the Industrial 4.0 era is digital literacy. Digital literacy is the ability to use information and communication technology (ICT) to obtain information and sort it out. The ICT skills of teachers in Pangkalan Kuras District, Pelalawan Regency are quite good. The indication is that most teachers are able to use social media which is accessed via smartphones and personal netbooks. However, this ability has not been utilized to implement a digital-based learning process in the classroom. This is because teachers still have limitations using smartphones or netbooks as online learning media. The Riau University Chemical Education Study Program offers training on making digital learning media based on Socrative for teachers in Pangkalan Kuras District as one of the community service activities. The teacher was enthusiastic about participating in the training held. Some teachers are able to apply Socrative-based learning in the classroom. Meanwhile, some others cannot implement digital-based learning in the classroom because of the lack of students who have smartphones and school regulations that do not allow students to use smartphones in school.

Keywords: Socrative, Digital Literacy, Socrative Based Learning

\section{PENDAHULUAN}

Perkembangan teknologi informasi dan

komunikasi (TIK) yang signifikan menyebabkan perubahan dalam tatanan kehidupan manusia. Pada saat ini, dunia sedang memasuki digitalisasi dalam industri yang disebut Industri 4.0. Industri 4.0 mengacu pada industri pintar yang serba otomatis, independen, dan menggunakan internet sebagai kontrol kendalinya (Kagermann, Wahlster, \& Helbig, 2013). Industri 4.0 memberikan dampak perubahan yang menyeluruh terhadap aspek kehidupan dalam masyarakat dan melahirkan tatanan kehidupan baru yang 
disebut Society 5.0. Society 5.0 merupakan suatu sistem tatanan masyarakat yang terhubung secara dinamis dengan adanya penerapan teknologi digital (Fukuyama, 2018). Tatanan masyarakat seperti ini hanya bisa tercipta untuk masyarakat yang mempunyai kemampuan literasi digital yang baik.

Literasi digital merupakan kemampuan seseorang dalam memahami dan menggunakan informasi dalam berbagai format dengan menitikberatkan pada berpikir kritis dibandingkan penggunaan teknologi informasi (Chan, dkk., 2017). Meski berbasis pada berpikir kritis, pada dasarnya literasi digital berkaitan dengan kemampuan seseorang dalam menggunakan internet sebagai sumber informasi (Tsaniyah \& Juliana, 2019). Oleh karena itu, penguasaan TIK merupakan kompetensi yang harus dimiliki untuk menghadapi era digitalisasi.

Tingkat literasi digital masyarakat Indonesia secara umum masih rendah kecuali di lingkungan kota besar, daerah wisata, industri, dan kampus (Kurnia \& Astuti, 2017). Usaha yang telah dilakukan pemerintah Indonesia dalam rangka meningkatkan literasi digital adalah dengan meluncurkan laman literasidigital.id pada tahun 2019 (Tsaniyah \& Juliana, 2019). Laman ini menyediakan bahan bacaan terkait literasi digital yang dapat diunduh secara gratis oleh masyarakat. Peran aktif masyarakat di segala bidang dibutuhkan untuk kesuksesan program ini, khususnya bidang pendidikan.

Pendidikan merupakan bidang yang berperan penting dalam menyebarluaskan ilmu pengetahuan melalui institusi pendidikan. Institusi pendidikan memiliki peran vital dalam mempersiapkan kompetensi yang harus dimiliki generasi masa depan agar mampu bersaing di era digital. Kompetensi yang dibutuhkan di era digital tentu berbeda dengan era sebelumnya. Oleh karena itu, seyogyanya pemerintah dan institusi pendidikan harus melakukan persiapan dan transformasi kebijakan dalam rangka mencapai kompetensi di era digital. Upaya yang dapat dilakukan diantaranya adalah penyesuaian kurikulum di era digital, penyediaan sarana dan prasarana TIK, serta mempersiapkan guru yang menguasai TIK (Syamsuar \& Reflianto, 2019).

Tingkat penguasaan TIK guru-guru di Indonesia masih tergolong rendah (Fitriyadi, 2013) apalagi guru di daerah terluar dan terpencil (Batubara, 2017). Padahal, guru harus mampu menguasai TIK dan strategi mengajar di era digital agar siswa merasakan pengalaman belajar yang menyenangkan. Oleh karena itu, perlu dilakukan pelatihan bagi guru untuk meningkatkan kompetensi guru dalam melakukan pembelajaran di era digital.

Pembelajaran di era digital menuntut penggunaan media online dalam proses pembelajaran (Cholily, dkk., 2019). Langkah awal yang dapat dilakukan untuk pembelajaran di era digital adalah dengan blended-learning. Blended-learning adalah proses pembelajaran yang menggabungkan pembelajaran tatap muka dan pembelajaran yang didukung oleh TIK (Lalima \& Lata Dangwal, 2017). Blendedlearning terbukti dapat meningkatkan kemampuan kognitif siswa dengan pemanfaatan platform online (Budiharti, Ekawati, Wahyuningsih, \& H, 2015). Berbagai platform online dapat digunakan sebagai media dalam blended-learning, diantaranya adalah Google Classroom, Zoom, Moodle, Edmodo, dan Socrative.

Socrative merupakan suatu sistem respons siswa yang dapat digunakan secara gratis dan berbayar yang dapat diunduh melalui laman www.socrative.com. Aplikasi ini menyediakan kuis interaktif sehingga siswa tidak bosan selama pembelajaran. Kuis yang tersedia diantaranya adalah pilihan ganda, benar atau salah, dan isian singkat. Hasil kerja siswa dapat diketahui oleh guru secara real time (Mendez \& Slisko, 2013). Hal ini akan memudahkan guru dalam memberikan umpan balik terhadap hasil kerja siswa. Socrative mampu menciptakan lingkungan pembelajaran aktif dan membantu meningkatkan partisipasi siswa dalam pembelajaran (Kaya \& Balta, 2016). Socrative dapat meningkatkan kemampuan siswa dan bisa digunakan sebagai media pembelajaran berbasis TIK (Aeni \& Lestari, 2018).

Kecamatan Pangkalan Kuras merupakan salah satu kecamatan yang ada di Kabupaten Pelalawan Provinsi Riau. Lembaga pendidikan di Kecamatan ini terdiri dari 34 SD, 10 SMP, 2 SMA, dan 2 SMK. Sedangkan jumlah guru, baik guru PNS, honorer, dan swasta berjumlah 600 guru SD, 274 guru SMP, 101 guru SMA, dan 43 guru SMK (Pelalawan, 2020).

Berdasarkan observasi awal di lapangan, sebagian besar guru, khususnya di daerah Sorek Satu, sudah menguasai TIK dengan cukup baik. Hal ini ditunjukkan oleh banyaknya guru mempunyai media sosial yang diakses melalui smartphone maupun netbook pribadi. Akan tetapi, kemampuan ini belum mereka manfaatkan untuk menerapkan proses 
pembelajaran berbasis digital di kelas. Hal ini bisa disebabkan guru masih memiliki keterbatasan menggunakan smartphone atau netbook sebagai media pembelajaran online. Oleh karenanya, guru di Pangkalan Kuras ingin dibantu dalam pembuatan media pembelajaran berbasis digital.

Program Studi Pendidikan Kimia Universitas Riau menawarkan pelatihan pembuatan media pembelajaran digital Socrative bagi guru-guru di Pangkalan Kuras agar guru dapat melaksanakan pembelajaran digital berbasis Socrative di kelas. Tawaran ini disambut baik oleh guru-guru di Pangkalan Kuras. Hal ini dibuktikan dengan adanya kesediaan pihak SMA Negeri 1 Pangkalan Kuras untuk menjadi tempat pelatihan.

Penggunaan Socrative sebagai media pembelajaran digital mampu meningkatkan keterlibatan dan hasil belajar siswa. Selain itu, Socrative dapat membantu guru dalam menilai kemampuan siswa secara real time sehingga guru dapat memberikan umpan balik secara efektif. Setelah mengikuti pelatihan pembuatan media pembelajaran berbasis Socrative, guru diharapkan dapat membuat media pembelajaran Socrative berdasarkan kreasinya sendiri dan diterapkan pada proses pembelajaran di kelas.

\section{METODE KEGIATAN}

Kegiatan pengabdian masyarakat ini dilakukan dengan terlebih dahulu melakukan observasi di lapangan untuk mencari tahu tentang pelaksanaan pembelajaran yang menggunakan media pembelajaran digital berbasis Socrative. Setelah itu dilakukan analisis terhadap permasalahan yang ada dan dicari solusinya. Langkah selanjutnya adalah melakukan persiapan pra-pelatihan berupa penyusunan materi pelatihan, angket evaluasi pelaksanaan pelatihan, jadwal pelatihan, dan tenaga ahli.

Materi pelatihan yang diberikan meliputi pengenalan tentang Socrative, pembuatan account, pengelolaan kelas, pembuatan soal, pengelolaan kuis, dan pengelolaan hasil respon siswa. Materi diberikan secara pendampingan dengan metode ceramah, demonstrasi, dan praktek. Praktek dilakukan oleh guru setelah materi diberikan. Selanjutnya, guru peserta pelatihan diminta untuk mengisi angket evaluasi berkaitan dengan pelatihan yang telah diberikan. Kegiatan yang dilakukan pasca pelatihan adalah melakukan pendampingan secara daring bagi guru dalam penerapan media pembelajaran Socrative di kelas.

\section{HASIL \& PEMBAHASAN}

Pengabdian masyarakat dilakukan oleh tim dosen dan mahasiswa Pendidikan Kimia Universitas Riau pada hari Jum'at tanggal 18 Oktober 2019 bertempat di SMA Negeri 1 Pangkalan Kuras. Peserta yang hadir terdiri dari 25 orang guru SD sampai SMA seperti terlihat pada Tabel 1. Kegiatan ini berjalan dengan lancar karena adanya koordinasi yang bagus antara panitia dan peserta pelatihan seperti terlihat pada Gambar 3.a.

Tabel. 1. Guru peserta pelatihan Socrative

\begin{tabular}{|c|c|c|}
\hline Jenjang Guru & Jumlah & Persentase \\
\hline SD & 5 & $20 \%$ \\
\hline SMP & 4 & $16 \%$ \\
\hline SMA & 16 & $64 \%$ \\
\hline Total & 25 & $100 \%$ \\
\hline
\end{tabular}

Aplikasi Socrative memiliki 3 jenis mode tergantung kebutuhan guru dalam memberikan kuis kepada siswanya, yaitu "Student Paced-Immediate Feedback", "Student Paced-Navigation", dan "Teacher Paced". Mode "Student Paced-Immediate Feedback" memungkinkan siswa menerima penjelasan segera atau umpan balik setelah menjawab setiap pertanyaan. Guru juga bisa memonitor progres siswa secara real time. Mode "Student Paced-Navigation" memungkinkan siswa untuk menavigasi pertanyaan sesuai keinginannya. Mereka bisa menavigasi apakah ingin menjawab, melanjutkan, atau mengoreksi pertanyaan kapan pun. Sedangkan mode "Teacher Paced" menjadikan guru sebagai operator utama yang bisa mengatur jalannya setiap pertanyaan. Guru bisa mengirimkan pertanyaan ke kelas yang berbeda dan mendapatkan hasil secara langsung untuk tiap kelas. Setelah siswa menjawab semua pertanyaan, guru bisa mendapatkan laporan hasil kerja siswa dalam format excel untuk keseluruhan kelas dan PDF sebagai individu.

Pada saat pelatihan, guru diajarkan dan didampingi bagaimana cara membuat account socrative sebagai student dan teacher serta bagaimana cara mengelola account Socrative agar berfungsi dengan baik. Peserta diperkenalkan dengan fitur-fitur yang ada pada Socrative student dan Socrative teacher sehingga guru dapat berkreasi sendiri dalam menggunakan fitur-fitur yang ada pada aplikasi 
Socrative. Selanjutnya, guru dilatih untuk menerapkan aplikasi Socrative dalam pembelajaran dengan cara melatih bagaimana cara menginput pertanyaan, memberikan jawaban yang benar, dan menjalankan aplikasi sebagai proses evaluasi pembelajaran siswa. Selain itu, guru juga dilatih bagaimana cara menginterpretasi hasil belajar siswa dengan menggunakan socrative dan cara membagikan karya yang telah dihasilkan dengan komunitas di aplikasi Socrative.

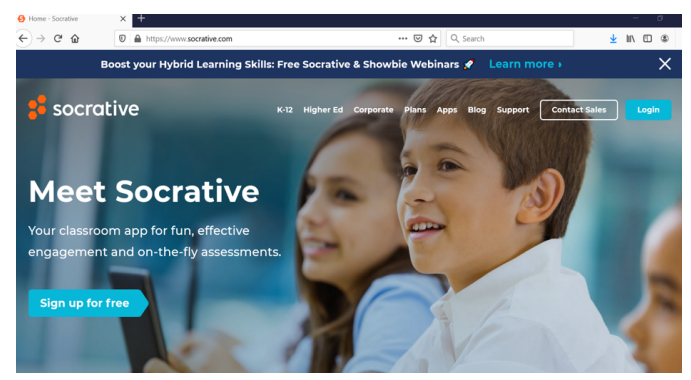

Gambar 1. Halaman utama Socrative

\section{Langkah-Langkah Membuat Kuis Online Menggunakan Socrative}

1. Buka tautan halaman web dari Socrative: www.socrative.com seperti Gambar 1.

2. Klik "get free account" untuk mendaftar secara gratis.

3. Kemudian akan muncul halaman untuk membuat kuis baru. Untuk membuat kuis, klik " Start Quiz".

4. Setelah itu, akan muncul halaman yang berisi nama dari Room dan klik create one untuk membuat kuis baru.

5. Kemudian akan muncul halaman untuk membuat judul dan jenis kuis yang akan dibuat. Pilih Multiple Choice untuk membuat kuis pilihan ganda. Pilih True / False untuk kuis benar / salah, dan pilih Short Answer untuk membuat kuis uraian singkat.

6. Setelah itu akan muncul halaman untuk membuat soal, jawaban, dan penjelasan dari soal tersebut. Klik tombol save untuk menyimpan soal. Apabila sudah yakin dengan soal dan jawabannya, klik save and exit di pojok kanan atas untuk keluar dan menyimpan soal.

7. Klik Start Quiz pada dashboard kemudian klik kuis yang akan dikerjakan oleh siswa. Klik start untuk memulai kuis

8. Hasil pekerjaan siswa akan ditampilkan secara real time dan guru bisa melihatnya.
9. Siswa dapat mengakses soal dengan memasukkan nama Room setelah login pada akun Socrative Student.

10. Setelah siswa selesai mengerjakan kuis, siswa mengklik submit pada akunnya.

Pada akhir pelatihan, guru diberikan angket seperti pada Tabel 2. Angket menggunakan skala Likert dengan rentang nilai 1 (sangat tidak setuju) sampai 5 (sangat setuju). Angket ini berfungsi untuk mendapatkan tanggapan dari peserta terhadap materi dan pelaksanaan pelatihan yang telah dilakukan. Selanjutnya dilakukan analisis terhadap hasil angket untuk mendapatkan masukan bagi tim pengabdi dalam meningkatkan kualitas pelatihan selanjutnya. Pada angket juga diminta saran dari guru tentang pelatihan apa yang diperlukan oleh guru sebagai bahan masukan bagi tim pengabdi untuk pengabdian yang akan dilakukan pada masa akan datang.

Tabel 2. Angket evaluasi pelatihan Socrative

\begin{tabular}{|c|l|}
\hline Indkator & \multicolumn{1}{|c|}{ Pernyataan } \\
\hline 1 & $\begin{array}{l}\text { Uraian materi pelatihan yang } \\
\text { disampaikan tim pengabdian dapat } \\
\text { diterima dengan baik }\end{array}$ \\
\hline 2 & $\begin{array}{l}\text { Materi yang diberikan informatif dan } \\
\text { bermanfaat }\end{array}$ \\
\hline 3 & $\begin{array}{l}\text { Dengan pelatihan ini Bapak/Ibu merasa } \\
\text { memperoleh gambaran yang kongkrit } \\
\text { tentang media pembelajaran berbasis } \\
\text { Socrative' }\end{array}$ \\
\hline 4 & $\begin{array}{l}\text { Media pembelajaran } \\
\text { 'Socrative'dapat membantu tugas } \\
\text { Bapak/Ibu sebagai guru di Kelas }\end{array}$ \\
\hline 5 & $\begin{array}{l}\text { Setelah mengikuti pelatihan Bapak/Ibu } \\
\text { mampu membuat media pembelajaran } \\
\text { berbasis 'Socrative'. }\end{array}$ \\
\hline 6 & $\begin{array}{l}\text { Setelah mengikuti kegiatan pelatihan } \\
\text { Bapak/Ibu tertarik mengembangkan } \\
\text { beberapa media pembelajaran berbasis } \\
\text { 'Socrative' }\end{array}$ \\
\hline 7 & $\begin{array}{l}\text { Tim pengabdian sangat berperan dalam } \\
\text { membimbing dan mengarahkan peserta } \\
\text { untuk menguasai trik pembuatan media } \\
\text { berbasis 'Socrative' }\end{array}$ \\
\hline $\begin{array}{l}\text { Pelaksanaan pelatihan pembuatan media } \\
\text { berbasis 'Socrative' ini sangat efektif }\end{array}$ \\
\hline $\begin{array}{l}\text { Waktu yang disediakan untuk pelatihan } \\
\text { mencukupi }\end{array}$ \\
\hline $\begin{array}{l}\text { Perlu dilaksanakan pelatihan yang } \\
\text { relevan secara berkesinambungan }\end{array}$ \\
\hline 8
\end{tabular}

Hasil angket dari penilaian peserta pelatihan Socrative menunjukkan bahwa pelaksanaan pelatihan mendapat respon positif dari peserta. Hampir semua indikator 
kepuasan mendapatkan nilai rata-rata diatas 3 seperti terlihat pada Gambar 2. Indikator yang mendapatkan nilai tertinggi adalah indikator 3 dan 4 yang berarti bahwa kegiatan pelatihan yang diadakan dapat meningkatkan wawasan dan keterampilan guru dalam menggunakan media pembelajaran Socrative dalam pembelajaran. Hasil ini sejalan dengan pengabdian yang dilakukan oleh Hadi dan kolega (2020). Mereka menyatakan bahwa pelatihan media Socrative yang dilakukan dapat meningkatkan kompetensi guru dalam melaksanakan pembelajaran daring.
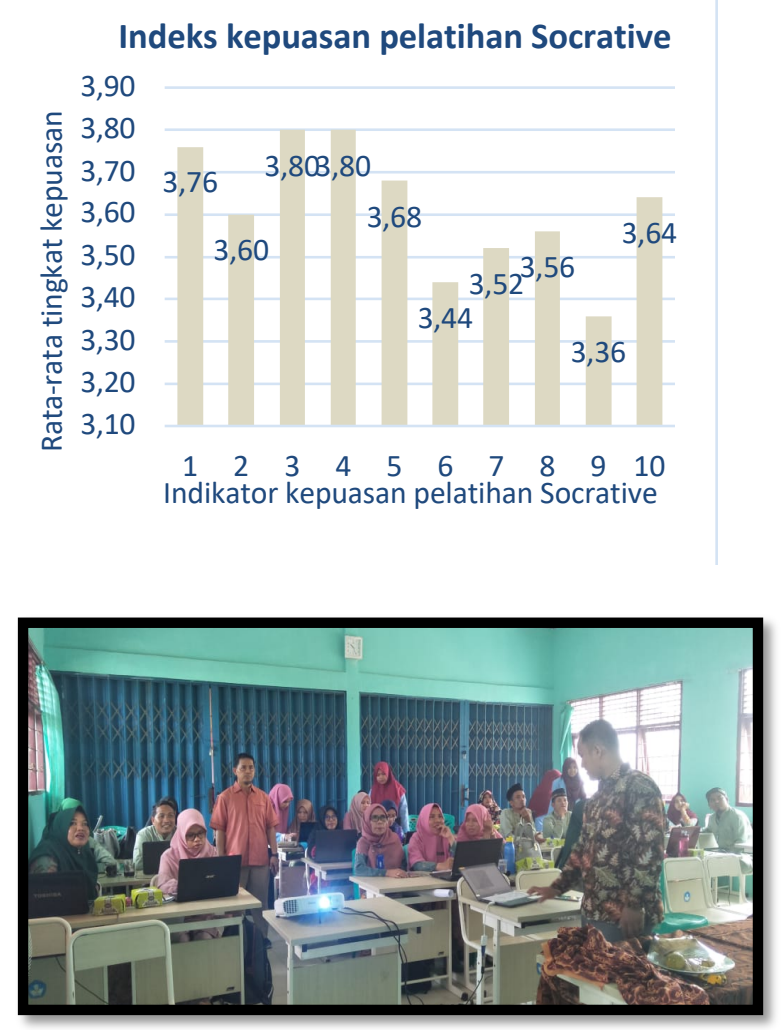

(a)
Gambar 3. (a) Pelatihan pembuatan media pembelajaran berbasis Socrative, (b) Implementasi
Pembelajaran berbasis Socrative di SMA

\section{Gambar 2. Grafik tingkat kepuasan Socrative}

Indikator yang mendapatkan nilai terendah adalah indikator 9 yang berkaitan dengan motivasi guru untuk menerapkan Socrative dalam pembelajaran setelah kegiatan pelatihan. Hal ini disebabkan oleh adanya beberapa sekolah yang menerapkan aturan bahwa peserta didik dilarang membawa alat komunikasi seperti smartphone ke sekolah. Padahal, agar dapat menggunakan aplikasi Socrative hal yang paling dibutuhkan adalah jaringan internet dan smartphone. Hambatan ini juga ditemukan oleh Rigianti (2020) dan Inggriyani dan kolega (2020), mereka menyatakan bahwa beberapa faktor yang menjadi hambatan guru dalam melaksanakan pembelajaran daring adalah minimnya jaringan internet dan kurangnya siswa memiliki smartphone.
Terdapat beberapa faktor pendukung dan penghambat yang mempengaruhi pelaksanaan dan hasil pengabdian masyarakat ini. Adapun faktor pendukungnya adalah adanya kerja sama yang baik antara tim pengabdi, pihak sekolah dan guru peserta pengabdian. Selain itu, antusias dari pihak peserta sangat membantu kelancaran acara ini sehingga berjalan dengan baik. Adapun faktor penghambat kegiatan ini adalah jaringan internet yang sering mengalami gangguan selama kegiatan berlangsung.

Pasca pelaksanaan pelatihan, guru peserta pelatihan diminta untuk bergabung kedalam kelompok Whats App yang dikelola oleh tim pengabdian. Tujuan pembuatan kelompok Whats App adalah untuk mendampingi guru secara daring dalam mengimplementasikan pembelajaran berbasis Socrative di sekolah masing-masing. Sebagian besar guru SMA mampu menerapkan pembelajaran Socrative di kelas. Salah satu yang berhasil menerapkan hal ini adalah guru SMA Negeri 1 Pangkalan kuras. Siswa terlihat serius dan antusias dalam pembelajaran terutama pada saat mengerjakan kuis berbasis Socrative yang diberikan oleh Guru seperti terlihat pada Gambar 3.b. 
Implementasi ini bisa terlaksana dengan baik karena semua siswa sudah mempunyai smartphone yang bisa digunakan untuk menjalankan aplikasi gratis. Sebagian besar guru SD dan SMP tidak bisa menerapkan pembelajaran berbasis Socrative di kelas karena tidak semua siswa mempunyai smartphone yang bisa digunakan untuk menjalankan aplikasi Socrative. Selain itu, adanya kebijakan beberapa sekolah melarang penggunaan smartphone di sekolah yang menghambat implementasi pembelajaran Socrative di sekolah.

\section{KESIMPULAN \& SARAN}

Penguasaan literasi digital diperlukan oleh guru dalam memudahkan guru melaksankan pembelajaran di era digital. Salah satu media pembelajaran digital yang dapat digunakan oleh guru adalah media Socrative. Pelatihan pembuatan media digital berbasis digital yang dilaksanakan oleh tim dosen dan mahasiswa Program Studi Pendidikan Kimia Universitas Riau untuk guru di Kecamatan Pangkalan Kuras dapat meningkatkan literasi digital guru dalam melaksanakan pembelajaran berbasis Socrative di kelas. Faktor pendukung kegiatan ini adalah adanya kerjasama yang baik antara panitia pelaksana dan antusiasme guru peserta pelatihan. Kendala yang dihadapi selama pelaksanaan pelatihan adalah adanya gangguan sinyal internet sehingga aplikasi tidak bisa dijalankan. Pasca pelatihan, sebagian guru sudah bisa menerapkan pembelajaran berbasis socrative di kelas. Sedangkan sebagian lagi tidak bisa menerapkan karena minimnya siswa yang mempunyai smartphone serta adanya larangan menggunakan smartpohe di sekolah khususnya bagi siswa Sekolah Dasar.

\section{DAFTAR PUSTAKA}

Aeni, E. S., \& Lestari, R. D. (2018). Penerapan Metode Mengikat Makna dalam Pembelajaran Menulis Cerpen pada Mahasiswa IKIP Siliwangi Bandung. Sematik, $\quad 7(1), \quad 1-13$. https://doi.org/10.22460/semantik.vXiX. XXX

Batubara, D. S. (2017). Kompetensi Teknologi Informasi dan Komunikasi Guru SD/MI (Potret, Faktor-faktor, dan Upaya Meningkatkannya). Muallimuna, 3(1), 48-65.

https://doi.org/10.31602/muallimuna.v3i1 .954
Budiharti, R., Ekawati, E. Y., Wahyuningsih, D., \& H, F. F. (2015). Penggunaan Blended Learning dengan Media Moodle untuk Meningkatkan Kemampuan Kognitif Siswa SMP. Cakrawala Pendidikan, 34(1), 140-148. https://doi.org/10.21831/cp.v1i1.4184

Cholily, Y. M., Putri, W. T., \& Kusgiarohmah, P. A. (2019). Pembelajaran di Era Revolusi Industri 4.0. Seminar Nasional Penelitian Pendidikan Matematika (SNP2M) 2019 UMT, 1-6.

Fitriyadi, H. (2013). Keterampilan TIK guru produktif SMK di Kabupaten Hulu Sungai Utara dan implementasinya dalam pembelajaran. Jurnal Pendidikan Vokasi, 2(2), 213-233. https://doi.org/10.21831/jpv.v2i2.1033

Fukuyama, M. (2018). Society 5.0: Aiming for a New Human-centered Society. Japan SPOTLIGHT, 27(Society 5.0), 47-50.

Hadi, F., Syafi'i, A., \& Isgandi, Y. (2020). Pelatihan Penerapan Pembelajaran Daring Interaktif Bagi Guru-Guru SD Al Islam Morowudi, Gresik. To Maega: Jurnal Pengabdian Masyarakat, 3(2), 142.

https://doi.org/10.35914/tomaega.v3i2.42 0

Inggriyani, F., Fazriyah, N., Hamdani, A. R., \& Purbasari, A. (2020). Pendampingan Model Pembelajaran Inovatif menggunakan Kahoot sebagai Digital Game Based Learning Di KKG Sekolah Dasar. Publikasi Pendidikan, 10(1), 59. https://doi.org/10.26858/publikan.v10i1.1 1992

Kagermann, Wahlster, W., \& Helbig, J. (2013). Recommendations for implementing the strategic initiative INDUSTRIE 4.0. Final Report of the Industrie $4.0 \mathrm{WG}$, (April).

Kaya, A., \& Balta, N. (2016). Taking Advantages of Technologies: Using the Socrative in English Language Teaching Classes. International Journal of Social Sciences \& Educational Studies, 2(3), 412.

Kurnia, N., \& Astuti, S. I. (2017). Peta Gerakan Literasi Digital Di Indonesia: Studi Tentang Pelaku, Ragam Kegiatan, Kelompok Sasaran Dan Mitra Yang Dilakukan Oleh Japelidi. Informasi:Kajian Ilmu Komunikasi, 47(2), 149-166. https://doi.org/10.21831/informasi.v47i2. 16079 
Lalima, D., \& Lata Dangwal, K. (2017). Blended Learning: An Innovative Approach. Universal Journal of Educational Research, 5(1), 129-136. https://doi.org/10.13189/ujer.2017.05011 6

Mendez, D., \& Slisko, J. (2013). Software Socrative and smartphones as tools for implementation of basic processes of active physics learning in classroom: An initial feasibility study with prospective teachers. European Journal of Physics Education, 4(2), n/a.

Pelalawan, B. (2020). Kabupaten Pelalalawan dalam Angka 2020 (B. Pelalawan, ed.). Pangkalan Kerinci: BPS Pelalawan.

Rigianti, H. A. (2020). Kendala Pembelajaran Daring Guru Sekolah Dasar Di Kabupaten Banjarnegara. Elementary School, 7(2), 297-302. Retrieved from https://www.golder.com/insights/blockcaving-a-viable-alternative/

Syamsuar, S., \& Reflianto, R. (2019). Pendidikan dan Tantangan Pembelajaran Berbasis Teknologi Informasi di Era Revolusi Industri 4.0. Jurnal Ilmiah Teknologi Pendidikan, 6(2), 1-13. https://doi.org/https://doi.org/10.24036/et .v2i2.101343

Tsaniyah, N., \& Juliana, K. A. (2019). Literasi Digital Sebagai Upaya Menangkal Hoaks di Era Disrupsi. Al-Balagh: Jurnal Dakwah Dan Komunikasi, 4(1), 121-140. https://doi.org/10.22515/balagh.v4i1.155 5 